\title{
Neurolymphomatosis of the Brachial Plexus and its Branches: Case Series and Literature Review
}

\author{
Pierre R. Bourque, Jodi Warman Chardon, Mark Bryanton, Melissa Toupin, \\ Bruce F. Burns, Carlos Torres
}

\begin{abstract}
Background: Neurolymphomatosis is a process of neoplastic endoneurial invasion, most strongly associated with nonHodgkin's lymphoma. It must be distinguished from paraneoplastic, metabolic, nutritional and treatment-related causes of neuropathy that are common in this patient population. Methods: This brief case series illustrates the protean manifestations of neurolymphomatosis of the brachial plexus, ranging from focal distal mononeuropathy to multifocal brachial plexopathy, either as the index manifestation of lymphoma or as a complication of relapsing disease. Results: Prominent asymmetry, pain and nodular involvement on neuroimaging may help distinguish neurolymphomatosis from paraneoplastic immune demyelinating radiculoneuropathy. MR neurography criteria for the diagnosis of neurolymphomatosis include hyperintensity on T2 and STIR sequences, focal and diffuse nerve enlargement with fascicular disorganization and gadolinium enhancement. No specific anatomical distribution within the brachial plexus has, however, been found to be characteristic. Fluorodeoxyglucose-positron emission tomography (FDG-PET) imaging is the imaging modality with the highest sensitivity for detection of nodal or extranodal spread in lymphoma. Conclusions: Brachial plexus neuropathy in neurolymphomatosis is highly protean in its distribution, semiology and relation to lymphoma staging. Dedicated MRI and PET-CT imaging are leading diagnostic modalities.
\end{abstract}

RÉSUMÉ: Neurolymphomatose du plexus brachial et de ses branches : étude de série de cas et recension des écrits. Contexte: La neurolymphomatose constitue un processus d'invasion endoneurale néoplasique le plus souvent associé à des lymphomes non hodgkiniens. Il doit ainsi être distingué de l'ensemble des causes de la neuropathie : paranéoplasiques, métaboliques, nutritionnelles ainsi que celles liées à l'administration d'un traitement. À noter que ces causes sont répandues au sein du groupe de patients à l'étude. Méthodes: Cette étude succincte d'une série de cas entend se pencher sur les manifestations protéiformes de la neurolymphomatose du plexus brachial, lesquelles, que ce soit comme indices de la présence de lymphomes ou résultant des complications d'une maladie récurrente, vont de la mono-neuropathie focale distale à la plexopathie brachiale multifocale. Résultats: Il est possible qu'une asymétrie importante, de la douleur et la présence de nodules détectés par neuro-imagerie contribuent à établir une distinction entre la neurolymphomatose et la radiculoneuropathie démyélinisante paranéoplasique d'origine immunitaire. Les critères diagnostiques de la neurolymphomatose au moyen de la neurographie par résonance magnétique (NRM) incluent notamment l'hyper-intensité en séquences STIR (pondération en T2) ainsi que l'augmentation focale et diffuse du volume des nerfs associée à une désorganisation fasciculaire et à l'utilisation du gadolinium afin d'améliorer le contraste des images. Cela dit, précisons qu'aucune distribution anatomique spécifique à l'intérieur du plexus brachial n'est apparue caractéristique. La tomographie par émission de positrons $\left({ }^{18} \mathrm{FDG}\right)$ est la modalité d'imagerie dont la sensibilité de contraste, la plus élevée, permet de détecter une propagation nodulaire ou extra-nodulaire dans le cas de lymphomes. Conclusions: Dans le cas de la neurolymphomatose, on a observé que la neuropathie du plexus brachial était grandement protéiforme tant en ce qui concerne sa distribution, sa sémiologie qu'en relation avec la stadification des lymphomes. Tant des examens spécifiques d'IRM que la tomographie par émission de positrons demeurent des techniques diagnostiques de premier plan.

Keywords: Neurolymphomatosis, Brachial plexus, Neuropathy, B-cell lymphoma, MR neurography

doi:10.1017/cjn.2017.282

Can J Neurol Sci. 2018; 45: 137-143

\section{INTRODUCTION}

Involvement of the peripheral nervous system occurs in $5 \%$ of patients with lymphoma, ${ }^{1}$ and may be noted at any stage in the disease evolution. Neurolymphomatosis (NL) refers to direct infiltration of the endoneurium by lymphoma cells, a process which must be distinguished from compression of nerves by adjacent lymphadenopathy or extranodal lymphomatous masses. Neurolymphomatosis must also be distinguished from meningeal

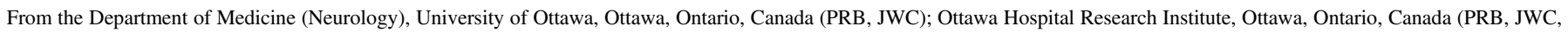
CT); Children's Hospital of Eastern Ontario, Ottawa, Ontario, Canada (JWC); Division of Nuclear Medicine, The Ottawa Hospital, Ottawa, Ontario, Canada (MB); Division of

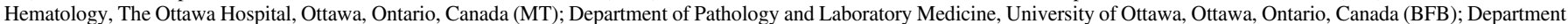
of Radiology, University of Ottawa, Ottawa, Ontario, Canada (CT)

Received June 30, 2017. Revised August 30, 2017. Date of Acceptance September 19, 2017.

Correspondence to: Dr. J. Warman Chardon, The Ottawa Hospital, 1053 Carling Avenue, Ottawa, ON K1H8L6, Canada. Email: jwarman@toh.ca 
Table 1: Case 1. Ulnar motor and sensory nerve conduction studies

\begin{tabular}{|l|c|c|c|}
\hline $\begin{array}{l}\text { Nerve/Stimulation } \\
\text { Site }\end{array}$ & Latency (ms) & Amplitude & Velocity (m/s) \\
\hline L Ulnar Motor / Abductor Digiti Minimi \\
\hline Wrist & 5.42 & $2.6 \mathrm{mv}$ & \\
\hline Below Elbow & 16.93 & $1.0 \mathrm{mv}$ & 16.5 \\
\hline Above Elbow & 19.01 & $0.9 \mathrm{mv}$ & 52.8 \\
\hline R Ulnar Motor / Abductor Digiti Minimi \\
\hline Wrist & 3.13 & $12.8 \mathrm{mv}$ & \\
\hline Below Elbow & 6.67 & $10.9 \mathrm{mv}$ & 55.1 \\
\hline Above Elbow & 8.65 & $10.1 \mathrm{mv}$ & 55.6 \\
\hline L Ulnar Sensory / Digit \# 5 & $\mathrm{NR}$ & $\mathrm{NR}$ & $\mathrm{NR}$ \\
\hline Wrist & \multicolumn{4}{|l}{} \\
\hline R Ulnar Sensory / Digit \# 5 & 2.97 & $14.5 \mu \mathrm{v}$ & 47.2 \\
\hline Wrist
\end{tabular}

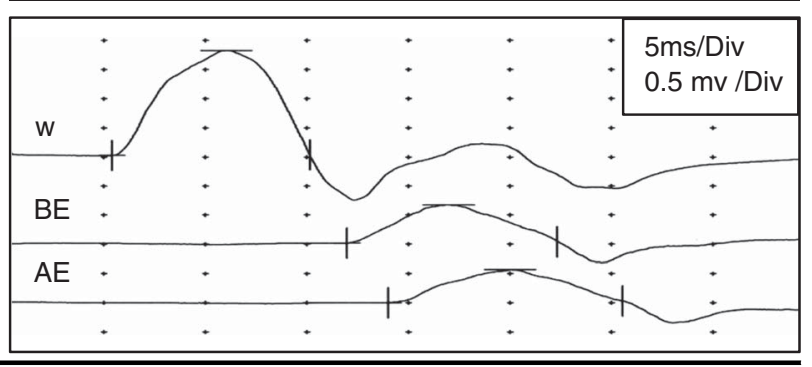

There is significant axonal loss on the left side (marked reduction in ulnar compound motor and sensory amplitudes with distal stimulation) as well as partial motor conduction block between Wrist and Elbow stimulation points (drop in amplitude from 2.6 to $1.0 \mathrm{mv}$, a $62 \%$ decrease). The tracings below represent the left ulnar compound muscle action potential waveform with stimulation at the wrist (W), below-elbow (BE) and above-elbow (AE) stimulation sites.

lymphomatosis (subarachnoid epineurial seeding without direct perivascular invasion of spinal nerve roots) $)^{2,3}$ and the wide range of immune-mediated paraneoplastic neuropathy. ${ }^{4}$ Several additional etiologies may contribute to the development of neuropathy in patients with lymphoma, such as chemotherapy, radiation toxicity, malnutrition and infection.

The present series illustrates patterns of brachial plexus invasion in lymphoma, ranging from focal distal mononeuropathy to nodular or diffuse brachial plexopathy. Emphasis will be given to the differential diagnosis of NL and the role of neuroimaging in diagnosis and staging.

\section{Case 1}

This patient first presented at age 48 with cutaneous B-cell non-Hodgkin lymphoma, stage 1EA, which was managed with local radiotherapy. At age 58, she had a recurrence with femoral adenopathy, treated with six cycles of Cytoxan, Hydroxyrubicin, Oncovin, Prednisone (CHOP) chemotherapy. At age 65, recurrent lymphoma required local radiotherapy and fludarabine. Subsequent cervical lymphadenopathy was treated with courses of cyclophosphamide and rituximab.

At age 78 she was referred to the neuromuscular clinic for symptoms of numbness, paresthesia and pain along the ulnar border of the left hand. There was well-delineated sensory loss in the ulnar territory. There was marked atrophy and weakness of
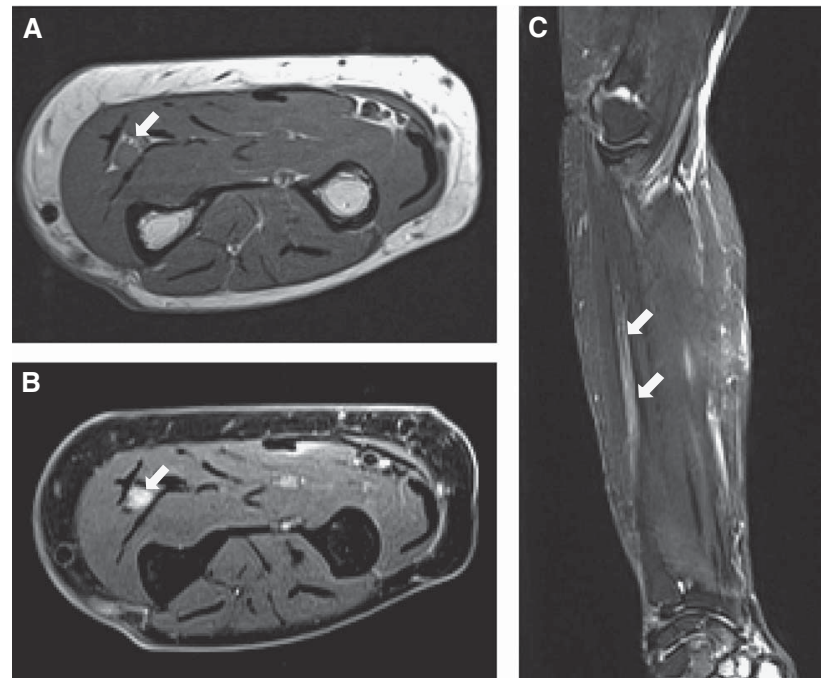

Figure 1: Case 1. Axial T1 (A), axial proton density with fat saturation (B) and coronal T2 sequence with fat saturation show a fusiform thickening of the left ulnar nerve, in the proximal-mid forearm (arrows). The signal intensity of the nerve is mildly increased in the axial PD and coronal T2 sequences with fat saturation.

all left interosseous muscles. Electrodiagnostic studies demonstrated marked motor and sensory axonal loss confined to the territory of the left ulnar nerve. There was also partial motor conduction block in the ulnar nerve in the proximal forearm, suggesting focal demyelination (Table 1). An FDG-PET/CT scan did not show evidence of recurrent systemic lymphoma, though the study, as per institutional protocol, excluded the forearm from the field of view. MRI of the forearm without gadolinium enhancement showed fusiform thickening of the left ulnar nerve over a length of $10 \mathrm{~cm}$, at the level of the proximalmid forearm (Figure 1).

At surgical exploration, the left ulnar nerve was focally enlarged and discolored. There was no recognizable fascicular pattern when the epineurium was entered. Pathological examination showed diffuse large B-cell lymphoma, with a non-germinal center phenotype (Figure 2). The patient was treated with combination chemotherapy (CHOP, rituximab) followed by adjuvant radiotherapy to the forearm (40Gy in 15 fractions). There was relief of pain without recovery in ulnar nerve function, and the patient remained in remission from lymphoma when last assessed at age 80 .

\section{Case 2}

This patient had an unrelated past history of grade 2 diffuse astrocytoma of the right post-central gyrus, treated with cranial radiation and temozolomide at age 37 . The only residual effect was partial epilepsy, well controlled with clobazam and levetiracetam.

At age 44, he noticed increasing stinging dysesthesia, as well as progressive numbness, on the lateral aspect of his right shoulder. This was associated with progressive asymmetric weakness of his upper limbs. There were no additional neurological or constitutional symptoms.

On examination, there was marked asymmetric weakness of both upper extremities. In the right upper limb, strength of most proximal muscles was graded $2 / 5$, while hand intrinsic muscles were $4-/ 5$. In the left upper limb, shoulder abduction was $4 / 5$, but hand intrinsic muscles were graded only $2 / 5$. Sensory testing was normal except for patchy hypoalgesia of the right forearm and hand. Upper limb 

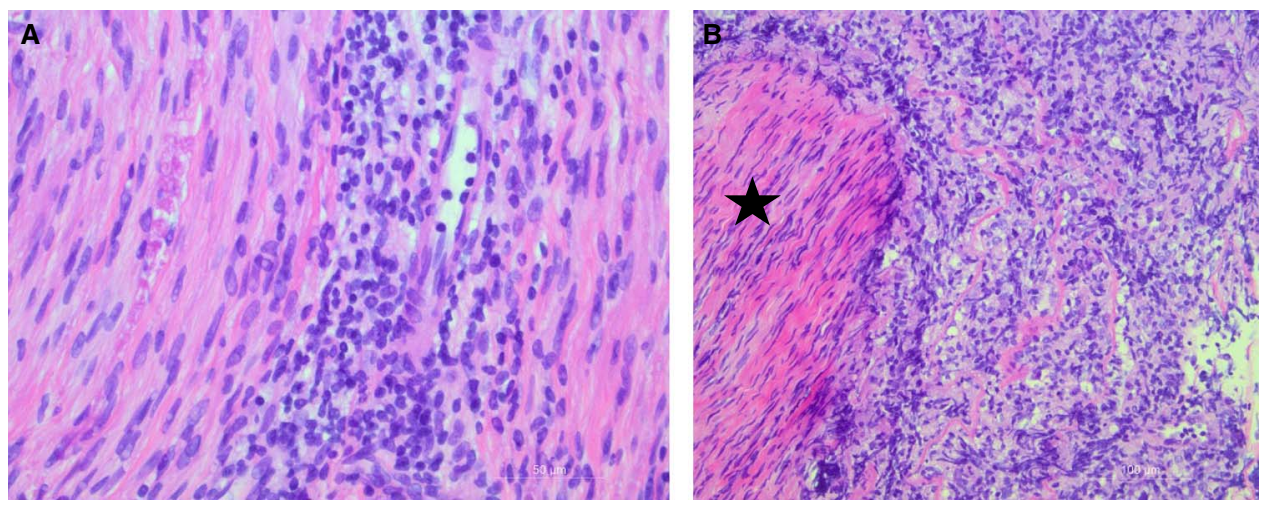

Figure 2: Case 1, biopsy of ulnar nerve. A: High power micrograph showing discrete lymphocytic infiltration within the endoneurium $(40 \times$ objective lens, $H \& E$ stain). B: Lower power micrograph showing infiltrate of atypical large lymphocytes around a nerve fascicle (star) $(20 \times$ objective lens, H\&E stain).

reflexes were symmetrically reduced, graded $1+$. Nerve conduction studies of the upper limbs were normal except for definite bilateral partial median nerve motor conduction blocks between Erb's point and axilla. Needle electromyography (EMG) showed definite patchy, asymmetric active denervation and reinnervation in the deltoid, biceps, triceps and hand intrinsic muscles. MRI of the brachial plexuses showed bilateral irregular thickening of trunks and divisions bilaterally, with additional areas of focal nodular enlargement and enhancement (Figure 3). Enhanced MRI of the entire spine was negative. Extensive blood work as well as CSF analysis was normal. The initial diagnosis was a multifocal variant of chronic inflammatory demyelinating polyneuropathy (CIDP).
The patient was first treated with intravenous immunoglobulins (IVIG). The response was equivocal, with improved strength of deltoid muscles, but worsening paresis of hand intrinsic muscles. Neuropathic pain in upper limbs also worsened, requiring treatment with narcotic analgesics. With the addition of Prednisone $60 \mathrm{mg}$ daily there was initial marked clinical improvement, which was not sustained during the steroid taper. Eight months after clinical onset, the patient noted a small nodule over the tragus of his right ear, showing rapid expansion (Figure 4). Punch biopsies revealed a diffuse large $\mathrm{B}$-cell lymphoma, with $\mathrm{ABC}$ phenotype and anomalous CD5 expression. ${ }^{18}$ FDG-PET/CT showed very extensive multifocal pattern of lymphomatous involvement (ear,
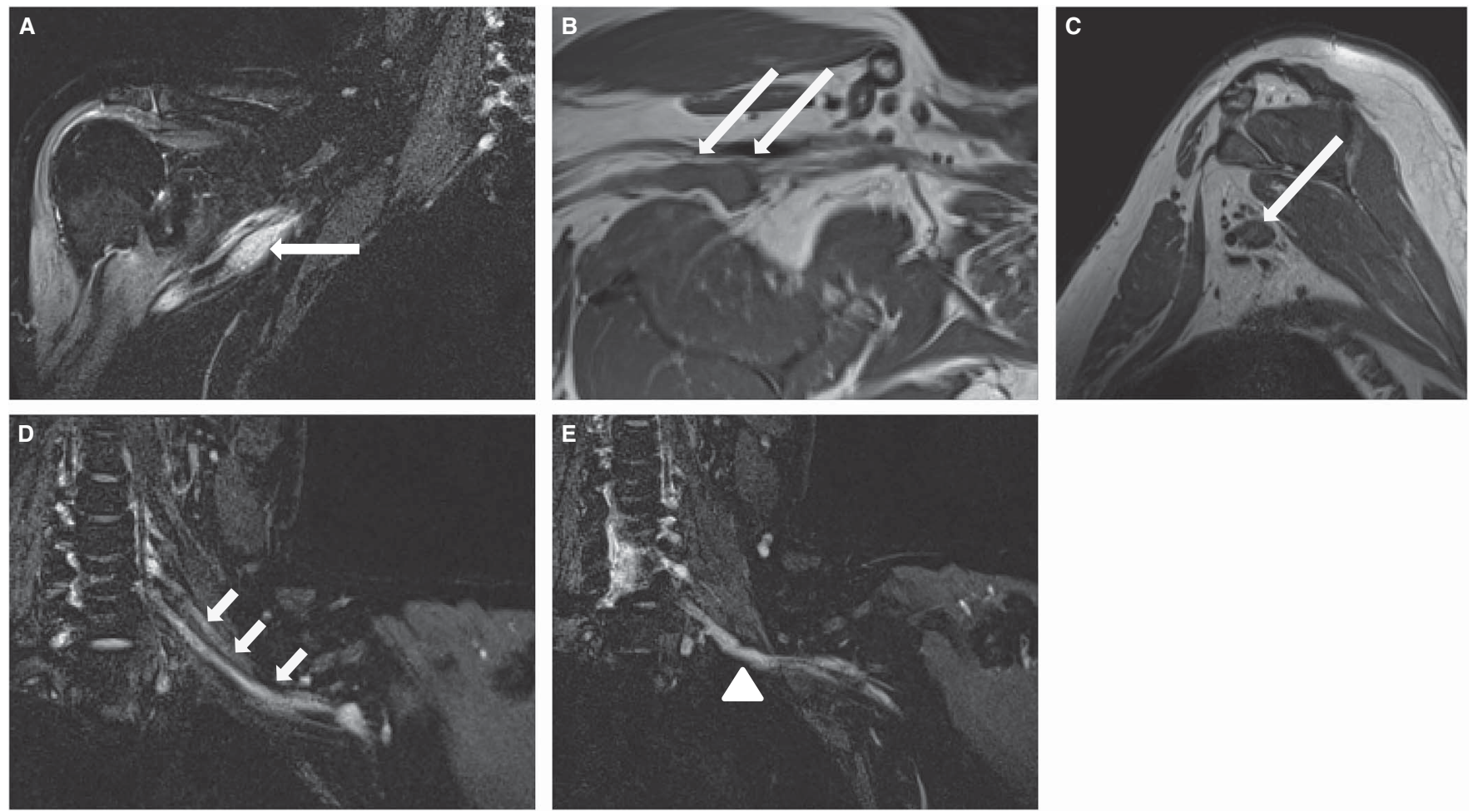

Figure 3: Case 2. Coronal short tau inversion recovery STIR (A), axial oblique $T 1(B)$ and sagittal T1W sequences $(C)$ of the right brachial plexus demonstrate focal nodular thickening of the posterior cord (long arrows), with associated increased signal in the STIR sequence. Coronal STIR sequences $(D, E)$ of the left brachial plexus show thickening of the visualized roots, trunks and divisions (short arrows), in particular of the lower trunk (arrowhead). 

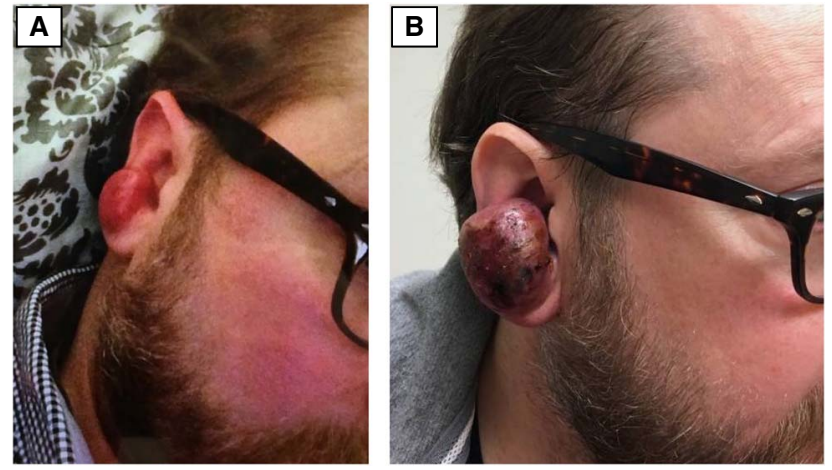

Figure 4: Case 2. Painless, rapidly expanding mass arising from the tragus of the right ear. This extranodal deposit led to the unexpected discovery of diffuse B-cell lymphoma. These two patient photographs $(A, B)$ are separated by only 20 days. There was equally rapid regression of the tumor mass within 2 weeks of initiation of chemotherapy.

parotid region, neck, axilla and pelvis). There was an $1.0 \times 0.6 \mathrm{~cm}$ nodule along the left brachial plexus with a Standardized Uptake Value (SUV) of 6.3. Similarly, in the right axilla, intense focal uptake (SUV of 6.9 ) in a $3.0 \times 2.2 \mathrm{~cm}$ soft tissue nodule corresponded to the brachial plexus thickening identified on MRI (Figure 5). The patient was started on R-CHOP chemotherapy, with an initial favorable response.

\section{Case 3}

This patient presented at age 62 with a testicular mass and widespread adenopathy from diffuse large B-cell lymphoma. $\mathrm{He}$ achieved initial remission with seven cycles of R-CHOP chemotherapy and testicular radiotherapy. He was also given prophylactic high-dose intravenous methotrexate. At age 66 he presented with recurrent inguinal lymphadenopathy.
As additional radiotherapy and chemotherapy were ineffective, he was offered autologous stem cell bone marrow transplantation. At age 67 he presented with motor deficits in the left upper limb, initially localized to the hand intrinsic and finger flexor muscles (C8 myotome). There was moderate pain in the left scapular region, and only mild paresthesia on the ulnar border of the hand. Within a few months, more widespread paresis was noted, involving the left triceps $(2 / 5)$, biceps $(4-/ 5)$, and all hand intrinsic muscles. Electrodiagnostic studies showed a pattern of axonal loss and active denervation in keeping with marked left brachial plexopathy.

Enhanced MRI of the cervical spine and CSF examination were normal. MRI of the left brachial plexus showed two distinct soft tissue masses with avid gadolinium enhancement, infiltrating the left brachial plexus at the level of the divisions and cords (Figure 6). The patient was treated with supraclavicular radiotherapy (35 Gy in 10 fractions) but was unable to tolerate additional chemotherapy. He was referred to palliative care.

\section{Discussion}

Neurolymphomatosis is a rare condition, with a marked preponderance $(90 \%)$ of non-Hodgkin lymphoma. ${ }^{5}$ Conversely, it is estimated that roughly $10 \%$ of non-Hodgkin lymphoma metastasize to peripheral nerves. In an autopsy series of 145 patients who died of lymphoma, some degree of peripheral nerve invasion was found in $40 \%$ of cases, though this particular series also included a large proportion of cases with leukemic conversion. ${ }^{6}$ In a literature review covering the period of 1973-2000, the diagnosis was only made at autopsy in $46 \%$ of cases. ${ }^{7}$ Improvements in neuroimaging led to antemortem diagnosis in $95 \%$ and $98 \%$ in the two largest subsequent case series covering the period of 2001-2008. ${ }^{5}$ The incidence of $\mathrm{NL}$ is also felt to be increasing, though it is not known whether this reflects a bias of greater diagnostic recognition, longer
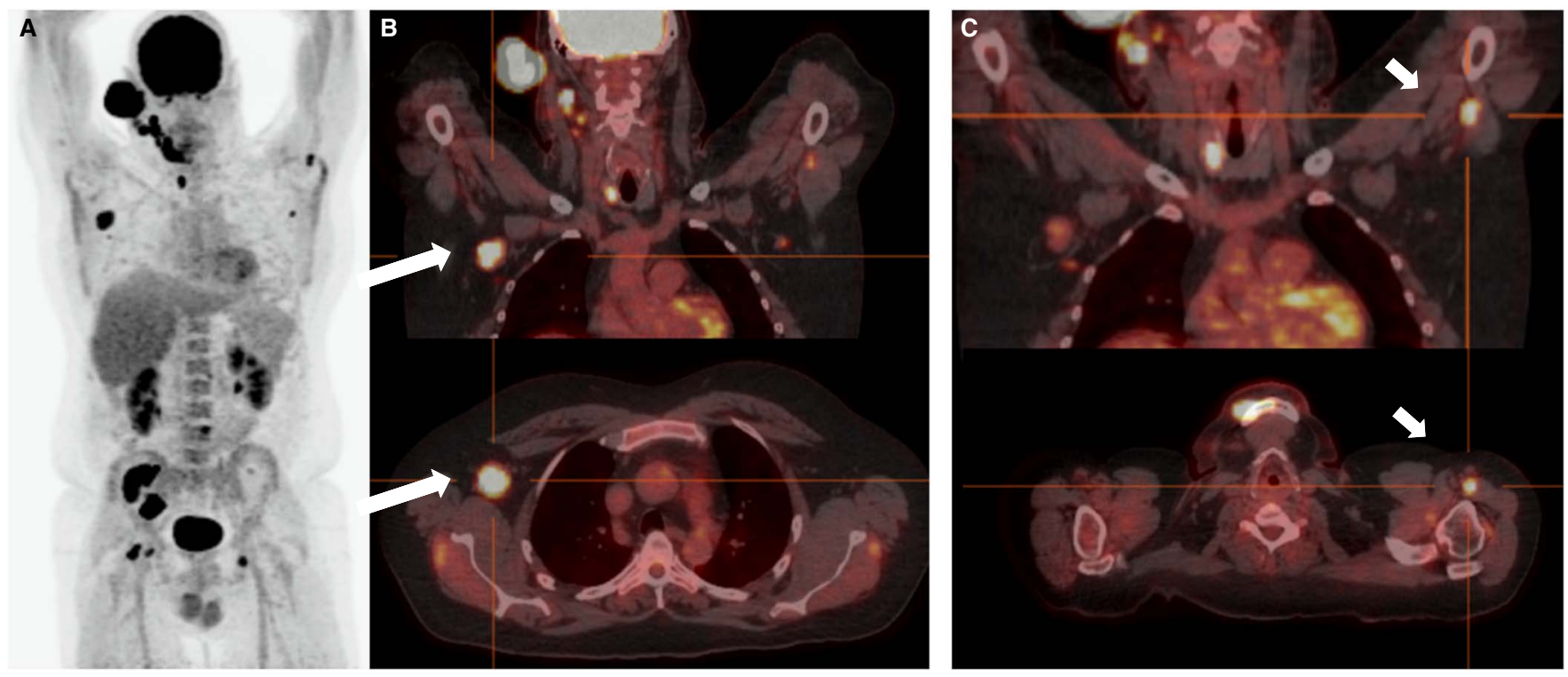

Figure 5: Case 2. A: Coronal ${ }^{18}$ FDG-PET showing widespread extranodal and nodal hypermetabolic foci. Note that intense uptake is a normal finding for the brain, optic nerves, kidneys and bladder. B and C: PET-CT fusion imaging in the coronal (top) and transverse (bottom) planes. There are areas of intense focal uptake at the level of the right axilla (long arrows) and distal left brachial plexus (short arrows ), in keeping with nodular neurolymphomatosis. 

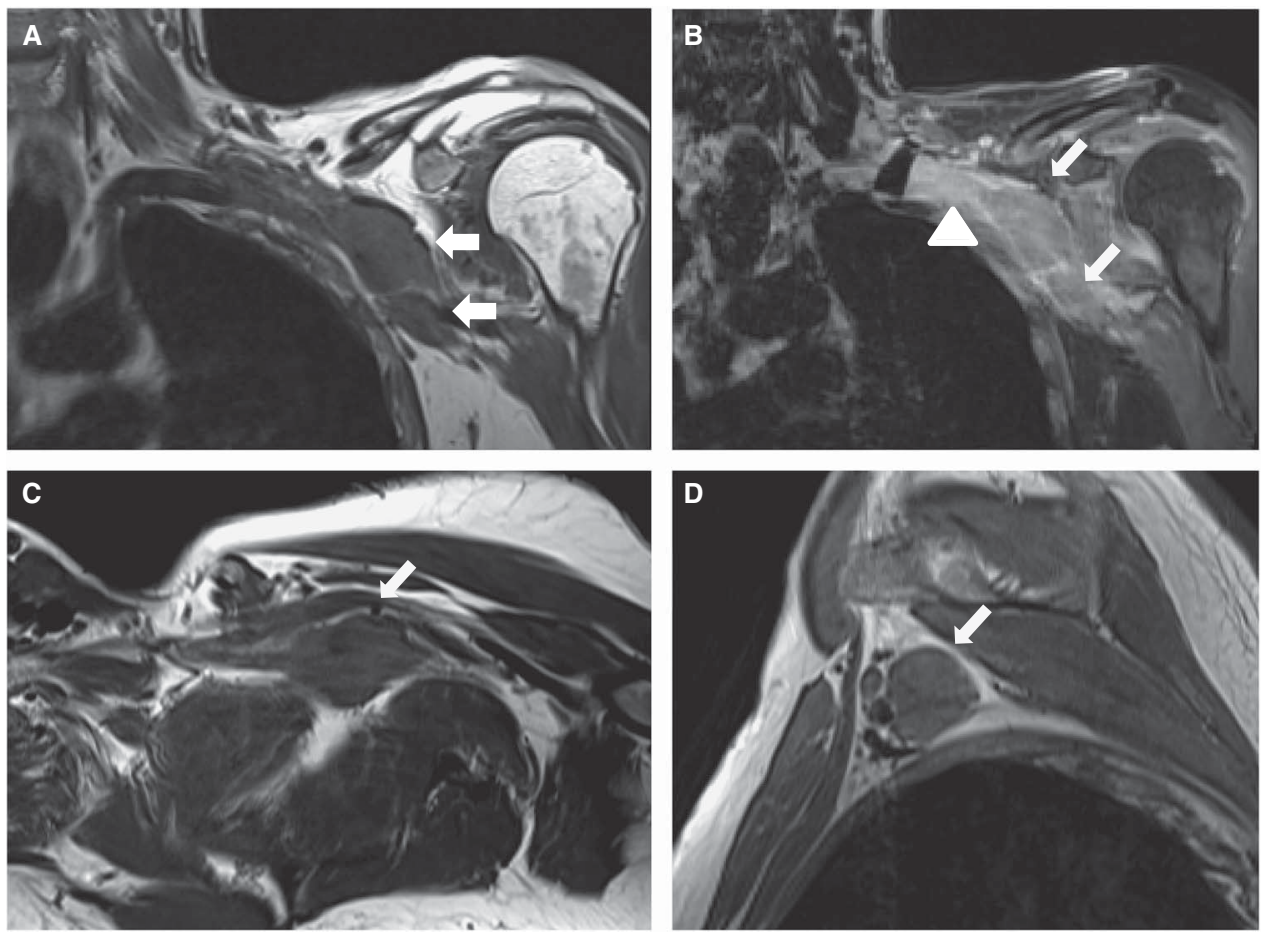

Figure 6: Case 3. Coronal T1 (A), coronal T1 with contrast and fat saturation (B), axial oblique T1 (C) and sagittal $T 1 W$ sequences $(D)$ of the left brachial plexus show focal masses (arrows) involving the distal cords and proximal branches. In addition, there is thickening, clumping and enhancement of the divisions (B) (arrowhead)

survival from modern therapy, or a true selection of neurotropic clones of lymphoma cells. Neurolymphomatosis is notorious for presenting as a clinically isolated neuropathic syndrome, with a highly protean anatomical distribution. ${ }^{8}$ This creates a diagnostic dilemma, particularly when neuropathy precedes the recognition of overt nodal or extranodal lymphomatous involvement.

Case 1 is an example of very focal upper limb NL, limited to a short segment of the ulnar nerve at the level of the proximal forearm. There have been few case reports of similar isolated involvement of the following distal branches of the brachial plexus: radial nerve (four cases), ${ }^{9-12}$ median nerve (three cases) ${ }^{13-15}$ and ulnar nerve (one case). ${ }^{16}$ With such mononeuropathies, at an anatomical location remote from common sites of entrapment, the initial differential diagnosis, in addition to NL, must include schwannoma, neurofibroma, hypertrophic neuritis, perineuroma, multifocal motor neuropathy and vasculitis.

Similarly, the trunks, divisions and cords of the brachial plexus may be involved in isolation as the first manifestation of NL. ${ }^{17-19}$ No specific anatomical distribution of brachial plexus involvement has been found to be characteristic of NL, in contrast to metastatic brachial plexopathy from breast or lung carcinoma (which commonly affects the lower trunk) (20,21 $^{2}$ or radiation plexopathy (with a relative predilection for the upper trunk). ${ }^{22,23}$ When there is no evidence of lymphoma on laboratory and imaging tests (CSF study, CT of thorax and abdomen, ${ }^{18}$ FDG-PET), surgical exploration and fascicular nerve biopsy may be necessary to reach a conclusive pathologic diagnosis. Nerve biopsy is, however, fraught with significant risk and morbidity, particularly at proximal sites such as the proximal plexus, spinal nerves or cranial nerves. ${ }^{5}$ Biopsy may be better justified at a distal limb location, or if there is already evidence of extensive axonal loss.
Case 2 illustrates the difficulty in distinguishing NL, which is a process of direct invasion of peripheral nerves, from paraneoplastic neuropathy, which covers a spectrum of remote, mostly immunemediated demyelinating, neuronal or axonal disorders. ${ }^{4}$ This patient had electrodiagnostic evidence of motor conduction block at the level of the brachial plexus, suggesting focal proximal demyelination, in keeping with the variant of CIDP known as multifocal acquired demyelinating motor and sensory neuropathy. MR imaging of the brachial plexus was first interpreted as in keeping with CIDP. This initial diagnostic conclusion was bolstered by temporary and partial improvement with both IVIG therapy and steroids. It was the appearance of a rapidly expanding lymphomatous deposit at the level of the external ear that led to the discovery and staging of systemic lymphoma with NL. ${ }^{18}$ FDG-PET was then the most conclusive imaging modality to document the distribution of lymphomatous spread.

The most common form of paraneoplastic neuropathy in lymphoma is a symmetrical demyelinating polyneuropathy, presenting rarely as Guillain-Barré syndrome or more commonly as CIDP..$^{18,24}$ Other paraneoplastic peripheral nervous system (PNS) syndromes in lymphoma include rare cases of subacute motor neuronopathy, ${ }^{25,26}$ sensory neuronopathy, ${ }^{27,28}$ and vasculitic neuropathy ${ }^{29,30}$ With the exception of the infrequent vasculitic neuropathy and the initial stages of sensory neuronopathy, paraneoplastic neuropathy tends to be more diffuse and symmetric in distribution. In contrast, a majority of patients with NL present with an asymmetric multifocal or mononeuropathic pattern of sensorimotor deficits. Pain is more often moderately to severely disabling, though relatively painless focal or diffuse neuro-pathy is also well documented. ${ }^{7}$

In the absence of pathological proof from CSF cytology, bone marrow aspiration, or biopsy of lymphadenopathy or extranodal 
disease, the distinction between NL and paraneoplastic neuropathy may be elusive. In a series of 32 patients with neuropathy associated with non-Hodgkin lymphoma, ${ }^{18}$ it was possible to classify 15 cases as pathologically proven or ${ }^{18}$ FDG-PET positive $\mathrm{NL}$ and five cases as likely paraneoplastic. The remaining 12 patients could not be conclusively classified in either of these two categories based on radiological or pathological criteria.

MRI neurography features of NL include: nerve enlargement, isointensity to muscle on T1, hyperintensity on T2 or STIR sequences, fascicular disorganization and significant focal or diffuse gadolinium enhancement. ${ }^{31,32}$ There is, however, considerable overlap with findings expected in etiologies that are in the differential diagnosis of NL, such as inflammatory demyelination or radiation. In equivocal cases, imaging may suggest an appropriate target site for biopsy and definitive tissue diagnosis. Case 3 of our series demonstrates the difficulty in distinguishing extrinsic compression and encasement of the brachial plexus from a marked focal nodular proliferation arising from primary intraneural lymphomatosis. The presence of enhancement and enlargement of neighboring cords, divisions and trunks adjacent to a focal tumor mass suggest true intraneural spread, but a conclusive distinction is often not within the limits of resolution of the MRI.

In a series combining the Massachusetts General Hospital experience and a review of the literature up to the year 2000, and thus reflecting older MR technology, Baehring ${ }^{7}$ reported that only 28 of 40 (70\%) cases of NL had documented nerve enlargement or enhancement on MRI. The diagnostic accuracy of MRI in NL improved to 28 of 35 cases $(80 \%)$ in a more recent literature review covering the 2001-2008 period. $^{5}$ In the three cases reported here, MRI played a key role in detecting lesions of the brachial plexus, though clinical context, ancillary studies and biopsy were required for a definitive diagnosis. In our case 2, the presence of large-diameter nodular enlargement of the brachial plexus likely pointed to NL rather than paraneoplastic inflammatory demyelinating neuropathy.

${ }^{18}$ FDG-PET/CT consistently reveals increased metabolic activity in the common aggressive lymphomas, with at least one ${ }^{18}$ FDG-avid lymphoma site detected in $100 \%$ for Hodgkin lymphoma and $97 \%$ for diffuse large B-cell lymphoma. ${ }^{33}$ There are no large scale studies of ${ }^{18}$ FDG-PET in the specific setting of NL. In a series of 50 cases of NL reported by the International Primary CNS Lymphoma Collaborative Group, ${ }^{18}$ FDG-PET was positive in $16 / 19(84 \%){ }^{5}$ These results may, however, mostly reflect the ability of PET to detect nodal or extranodal lymphoma in extraneural locations. Indeed, Case 2 demonstrates how ${ }^{18}$ FDG-PET may be better able to demonstrate hypermetabolism in nodular disease, with intense uptake demonstrated in these locations, and only mild asymmetry identified in regions of suspected infiltrative neural involvement. Although a post-therapy scan is not yet available for this patient, there are several articles demonstrating the use of ${ }^{18}$ FDG-PET to assess for treatment response in NL. ${ }^{34-36}$

Survival rates for patients with diffuse large B-cell lymphoma have been stratified according to the International Prognostic Index (IPI), which takes into account the patient's age, lactate dehydrogenase (LDH) level, performance status, stage of distribution of adenopathy and presence of extranodal involvement. With modern chemotherapy regimens, the 3 year estimate for overall survival is in the range of $60 \%$ for the subgroup with highest IPI scores (4-5). ${ }^{37}$ In contrast, Grisariu ${ }^{5}$ reported a 36month survival proportion of only $24 \%$ for patients with NL, though the majority showed an initial clinical and radiographic improvement with therapy. Radiotherapy has a limited role to control localized nerve involvement, particularly if there is disabling neuropathic pain, and systemic chemotherapy with rituximab and CHOP is the critical management option. High-dose IV MTX is often added. It has good penetration of the blood-brain and blood-nerve barriers, and may help prevent central nervous system relapses. ${ }^{38}$

This case series exemplifies how brachial plexus involvement in NL is highly protean in its neuroanatomic distribution and clinical evolution. Neurolymphomatosis remains a diagnostic challenge, particularly in cases where it precedes overt lymphoma, or manifests after prolonged remission. The combination of dedicated MRI neurography and PET-CT has greatly improved diagnostic accuracy, though clinical acumen remains paramount.

\section{DisCLOSURES}

The authors have no financial or other conflicts of interests relevant to this manuscript to disclose.

\section{STATEMENT OF AUTHORSHIP}

PRB: identification of case series, data collection, project supervision, drafting and revision of manuscript. JWC: critical revision of manuscript. MB: selection and annotation of Figure 5 and discussion of the role of PET imaging in NL. Review of manuscript. MT: review of manuscript, with special emphasis on treatment of lymphoma. BFB: Preparation of Figure 2 and neuropathology discussion. CT: Selection and discussion of MRI imaging figures and legends, critical review of manuscript.

\section{REFERENCES}

1. Hughes RA, Britton T, Richards M. Effects of lymphoma on the peripheral nervous system. J R Soc Med. 1994;87:526-30.

2. Lachance DH, O'Neill BP, MacDonald DR, et al. Primary leptomeningeal lymphoma: report of 9 cases, diagnosis with immunocytochemical analysis, and review of the literature. Neurology. 1991;41:95-100

3. Stark AM, Mehdorn HM. Leptomeningeal metastasis of an intradural malignant peripheral nerve sheath tumor. J Clin Neurosci. 2013; 20(8):1181-3

4. Graus F, Arino H, Dalmau J. Paraneoplastic neurological syndromes in Hodgkin and non-Hodgkin lymphomas. Blood. 2014;123 (2):3230-8.

5. Grisariu S, Avni B, Batchelor TT, van den Bent MJ, Bokstein F, Schiff D. Neurolymphomatosis: an International Primary CNS Lymphoma Collaborative Group report. Blood. 2010;115:5005-11.

6. Jellinger K, Radiaszkiewiez T. Involvement of the central nervous system in malignant lymphomas. Virchows Arch A Pathol Anat Histol. 1976;370:345-62.

7. Baehring JM, Damek D, Maring EC, Betensky RA, Hochberg FH. Neurolymphomatosis. Neuro Oncol. 2003;5:104-15.

8. Bower SP, McKelvie P, Peppard RW, Roberts L. Neurolymphomatosis presenting as mononeuritis multiplex. J Clin Neurosci. 1999;6(6):530-2.

9. Misdraji J, Ino Y, Louis DN, Rosenberg AE, Chiocca EA, Harris NL. Primary lymphoma of peripheral nerve: report of four cases. Am J Surg Pathol. 2000;24:1257-65.

10. Gonzalvo A, McKenzie C, Harris M, Biggs M. Primary nonHodgkin's lymphoma of the radial nerve: case report. Neurosurgery. 2010;67:E872-3.

11. Del Grande A, Sabatelli M, Luigetti M, et al. Primary multifocal lymphoma of peripheral nervous system: case report and review of the literature. Muscle Nerve. 2014;50:1016-22. 
12. van Bolden $\mathrm{V}$, Kline DG, Garcia CA, vanBolden GD. Isolated radial nerve palsy due to metastasis from a primary malignant lymphoma of the brain. Neurosurgery. 1987;21:905-9.

13. Desta K, O'Shaughnessy M, Milling MA. Non-Hodgkin's lymphoma presenting as median nerve compression in the arm. J Hand Surg Br. 1994;19:289-91.

14. van den Bent MJ, de Bruin HG, Beun GD, Vecht CJ. Neurolymphomatosis of the median nerve. Neurology. 1995; 45(7):1403-5.

15. Kim J, Kim YS, Lee EJ, Kang CS, Shim SI. Primary CD56-positive NK/T-cell lymphoma of median nerve: a case report. J Korean Med Sci. 1998;13:331-3.

16. Teissier J. Primary malignant lymphoma localized in the trunk of the ulnar nerve at the elbow. A case report. Ann Chir Main Memb Super. 1992;11:170-2.

17. Liang R, Kay R, Maisey MN. Brachial plexus infiltration by non-Hodgkin's lymphoma. Br J Radiol. 1985;58(695):1125-7.

18. Tomita M, Koike H, Kawagashira Y, et al. Clinicopathological features of neuropathy associated with lymphoma. Brain. 2013; 136:2563-78.

19. Choi YJ, Shin JA, Kim YH, et al. Neurolymphomatosis of brachial plexus in patients with non-Hodgkin's lymphoma. Case Rep Oncol Med. 2013;2013:492329.

20. Iyer VR, Sanghvi DA, Merchant N. Malignant brachial plexopathy: a pictorial essay of MRI findings. Indian J Radiol Imaging. 2010; 20(4):274-8.

21. Sureka J, Cherian RA, Alexander M, et al. MRI of brachial plexopathies. Clin Radiol. 2009;64(2):208-18.

22. Jaeckle KA. Neurologic manifestations of neoplastic and radiationinduced plexopathies. Semin Neurol. 2010;30(3):254-62.

23. Mondrup K, Olsen NK, Pfeiffer P, Rose C. Clinical and electrodiagnostic findings in breast cancer patients with radiationinduced brachial plexus neuropathy. Acta Neurol Scand. 1990; 81(2):153-8.

24. Vallat JM, De Mascarel HA, Bordessoule D, et al. Non-Hodgkin malignant lymphomas and peripheral neuropathies - 13 cases. Brain. 1995;118(Pt 5):1233-45.

25. Schold SC, Cho ES, Somasundaram M, Posner JB. Subacute motor neuronopathy: a remote effect of lymphoma. Ann Neurol. 1979; 5(3):271-87.
26. Flanagan EP, Sandroni P, Pittock SJ, Inwards DJ, Jones LK. Paraneoplastic lower motor neuronopathy associated with Hodgkin lymphoma. Muscle Nerve. 2012;46(5):823-7.

27. Maslovsky I, Volchek L, Blumenthal R, Ducach A, LUgassy G. Persistent paraneoplastic neurologic syndrome after successful therapy of Hodgkin's disease. Eur J Haematol. 2001;66(1): 63-5.

28. Plante-Bordeneuve V, Baudrimont M, Gorin NC, Gherardi RK. Subacute sensory neuropathy associated with Hodgkin's disease. J Neurol Sci. 1994;121(2):155-8.

29. Zivkovic SA, Ascherman D, Lacomis D. Vasculitic neuropathy electrodiagnostic findings and association with malignancies. Acta Neurol Scand. 2007;115(6):432-6.

30. Vincent D, Gombert B, Vital A, Vital C. A case of mononeuropathy multiplex with type II cryoglobulinemia, necrotizing vasculitis and low grade B cell lymphoma. Clin Neuropathol. 2007;26(1): 28-31.

31. Chhabra A, Andreisek G, Soldatos T, et al. MR neurography: past, present, and future. AJR Am J Roentgenol. 2011;197(3):583-91.

32. Thawait SK, Chaudhry V, Thawait CK, et al. High-resolution MR neurography of diffuse peripheral nerve lesions. Am J Neuroradiol. 2011;32:1365-72.

33. Weiler-Sagie M, Bushelev O, Epelbaum R, et al. (18) F-FDG avidity in lymphoma readdressed: a study of 766 patients. J Nucl Med. 2010;51:25-30

34. Lin M, Kilanowska J, Taper J, Chu J. Neurolymphomatosis diagnosis and assessment of treatment response by FDG PET-CT. Hematol Oncol. 2008;26(1):43-5.

35. Gykiere P, Jans L, Degrieck B, Goethals I. Neurolymphomatosis on 18F-FDG PET/CT: diagnosis and therapy response. Clin Nucl Med. 2016;41(2):142-3.

36. Trojan A, Jermann M, Taverna C, Hany TF. Fusion PET-CT imaging of neurolymphomatosis. Ann Oncol. 2002;13(5):802-5.

37. Ziepert M, Hasenclever D, Kuhnt E, et al. Standard international prognostic index remains a valid predictor of outcome for patients with aggressive $\mathrm{CD} 20+\mathrm{B}$-cell lymphoma in the rituximab era. J Clin Oncol. 2010;28(14):2373-80.

38. Lagarde S, Tabouret E, Matta M, et al. Primary neurolymphomatosis diagnosis and treatment: a retrospective study. J Neurol Sci. 2014;342:178-81. 